Haben Sie Fragen zur Abrechnung oder zur wirtschaftlichen Praxisführung? Als Leser der MMW können Sie sich an unseren Experten wenden: Helmut Walbert, Facharzt für Allgemeinmedizin und Betriebswirt aus Würzburg.

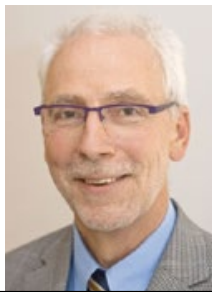

Helmut Walbert

Allgemeinarzt,

Medizinjournalist und

Betriebswirt Medizin

\title{
Aut-idem-Kreuz auch bei Generika möglich
}

$?$ Dr. P. G., Hausarzt-Internist, Hessen: Der Apotheker tauscht häufig auch Generika aus - selbst wenn die Kasse einen Rabattvertrag für das verordnete Präparat hat. Kann ich das per Aut-idem-Kreuz verhindern?

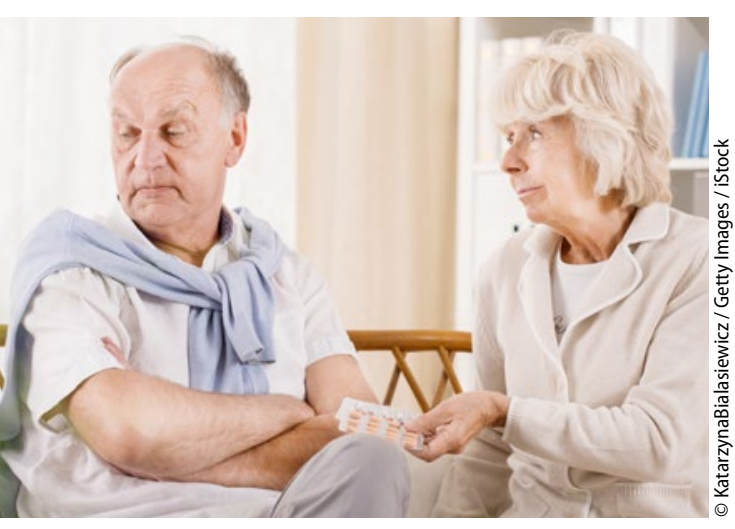

Tablettenwechsel können die Adhärenz bedrohen - auch bei Generika.
MMW-Experte Walbert: Für die Verschreibung von Generika gelten dieselben Aut-Idem-Regeln wie für Orginalpräparate. Grundsätzlich hat der Apotheker ein Recht auf Substitution, also die Abgabe eines wirkstoffgleichen Präparats. Gibt es für die verordnete Substanz ein rabattiertes Präparat, muss er sogar substituieren. Hat die Krankenkasse für die Substanz mehrere Rabattverträge, kann in der Apotheke nach Vorratslage gewählt werden.

Der verordnende Arzt kann diese nicht vorhersehbare Auswahl durch das Setzen des Aut-idem-Kreuzes ausschließen. Dafür gibt es eine Reihe von triftigen Gründen. Häufig muss z. B. auf eine Laktoseunverträglichkeit des Patienten geachtet werden. Auch gibt es allergische Reaktionen auf Farb- und Konservierungsstoffe. Es ist sogar über anaphy- laktoide Reaktionen auf Gelatine, Polysorbat oder D-Mannitol berichtet worden. Erinnert sei auch an die Warnung des Bundesinstituts für Arzneimittel und Medizinprodukte (BfArM) vor Chlorhexidin-Allergien.

Auch die Darreichungsform, die Tablettengröße oder die Teilbarkeit können das Aut-idem-Kreuz begründen. Mit einem Wechsel kommen manche Patienten nicht zurecht. Das Erhalten der Adhärenz gerade bei älteren, möglicherweise schon leicht dementen Patienten kann das Kreuz sinnvoll machen.

Mittlerweile gelten in vielen Verordnungsrichtlinien Generika grundsätzlich als wirtschaftlich. Ein Aut-idemKreuz ist bei Generika also immer ohne Regressangst möglich. Das Patientenwohl sollte weiterhin im Vordergrund stehen.

\section{Personalgespräch mit dauerkranker Mitarbeiterin?}

? Dr. H. G., Allgemeinarzt, Bayern: Ich habe eine Mitarbeiterin, die aufgrund einer Tumorerkrankung immer wieder ausfällt und auch jetzt wieder seit Längerem erkrankt ist. Ich würde gerne ein Personalgespräch über unsere gemeinsame Zukunft mit ihr führen, weiß aber nicht genau, welchen Rahmen ich wählen soll. Kann ich sie dazu in die Praxis einbestellen oder muss ich sie zu Hause besuchen?
.

MMW-Experte Walbert: Es ist weder ein Gespräch in der Praxis noch bei der Mitarbeiterin zu Hause sinnvoll! Diese Frage ist derzeit rechtlich ungeklärt und beim Bundesarbeitsgericht (BAG) anhängig. Wie wir alle wissen, gelten erkrankte Mitarbeiter grundsätzlich als komplett von der Arbeit freigestellt, wenn eine Arbeitsunfähigkeitsbescheinigung vorgelegt wird. Personalgespräche zählen aber zur Arbeitszeit und erfordern einen „gesunden“ Mitar- beiter. So hat es zumindest das Landesarbeitsgericht Nürnberg in einem Urteil entschieden (Az.: 7 Sa 592/14).

Die Richter begründeten ihre Entscheidung damit, dass der Arbeitgeber nicht darstellen konnte, warum das Personalgespräch zwingend im Krankenstand erfolgen musste. Ein unaufschiebbarer Gesprächsbedarf habe offensichtlich nicht vorgelegen. Unter dem Aktenzeichen 2 AZR 855/15 ist das Verfahren nun beim BAG anhängig. 